\title{
Cost-Effectiveness of Stronger Woodframe Buildings
}

\author{
Keith A. Porter, ${ }^{\text {a) }}$ M.EERI, Charles R. Scawthorn, ${ }^{\text {b) }}$ M.EERI, \\ and James L. Beck, ${ }^{\text {a) }}$ M.EERI
}

We examine the cost-effectiveness of improvements in woodframe buildings. These include retrofits, redesign measures, and improved quality in 19 hypothetical woodframe dwellings. We estimated cost-effectiveness for each improvement and each zip code in California. The dwellings were designed under the CUREE-Caltech Woodframe Project. Costs and seismic vulnerability were determined on a component-by-component basis using the Assembly Based Vulnerability method, within a nonlinear time-history structural-analysis framework and using full-size test specimen data. Probabilistic site hazard was calculated by zip code, considering site soil classification, and integrated with vulnerability to determine expected annualized repair cost. The approach provides insight into uncertainty of loss at varying shaking levels. We calculated present value of benefit to determine cost-effectiveness in terms of benefit-cost ratio (BCR). We find that one retrofit exhibits BCRs as high as 8, and is in excess of 1 in half of California zip codes. Four retrofit or redesign measures are cost-effective in at least some locations. Higher quality is estimated to save thousands of dollars per house. Results are illustrated by maps for the Los Angeles and San Francisco regions and are available for every zip code in California. [DOI: 10.1193/1.2162567]

\section{INTRODUCTION}

The purpose of this paper is to assess the cost-effectiveness of various levels of seismic design and construction quality, both new and retrofit, for woodframe residential buildings in California. The research was performed as part of the larger CUREECaltech Woodframe Project. We begin by providing some background on the project, and then detail our analysis and findings.

The CUREE-Caltech Woodframe Project. California's recent earthquake history, and particularly the 1994 Northridge earthquake, show that moderate earthquakes can be costly and deadly, and that losses in woodframe construction contribute substantially to both economic and life-safety risk. To mitigate this risk, it is worthwhile to examine the structural behavior and economic seismic performance of woodframe construction. The CUREE-Caltech Woodframe Project, funded by a \$5.2M grant from FEMA, involved laboratory, desktop, and field studies of the structural and economic performance of residential woodframe construction. (See CUREE [2003] for an overview.) The project en-

\footnotetext{
a) California Institute of Technology, 1200 E California Blvd MC 104-44, Pasadena, CA 91125

b) Department of Urban Management, Kyoto University, Kyoto 606-8501 Japan
} 
tailed approximately 30 sub-awards in five general thrust areas: laboratory testing, field investigations, building codes, economic modeling, and education. This paper summarizes the economic-modeling study (Porter et al. 2002a) and adds new material from subsequent study of benefit on a broad geographic basis. These projects had the following objectives:

- A fundamental improvement in loss modeling. We set out to improve loss estimation for woodframe buildings by demonstrating a methodology that allows one to compare directly the costs of retrofitting a woodframe dwelling (or of designing to above-code standards, changing a design procedure, or improving construction quality) with the resulting benefit in terms of reduced future repair costs. Existing techniques do not provide for such a direct comparison, for two reasons. First, whole-building loss data from past earthquakes are inadequate in quantity and detail to distinguish the economic benefit of retrofit or redesign. Second, existing analytical techniques to estimate repair costs rely so heavily on expert opinion that conclusions are difficult to defend scientifically. Our approach is distinguished from others in several ways: (1) more accurate structural modeling; (2) use of new laboratory test data and analytical tools produced by the CUREE-Caltech Woodframe Project; (3) professional cost estimates of initial construction, retrofit, and detailed repair efforts; and (4) treatment of line-ofsight costs to reflect the practice of repainting undamaged components to achieve reasonable uniform appearance.

- Benefit of retrofit and redesign measures. We set out to analyze the seismic vulnerability and economic benefit of detailed design and retrofit alternatives for individual buildings, to establish scientifically defensible benefit-cost analyses. To meet this objective, it is necessary to model the seismic structural response, damage, and repair cost of individual woodframe buildings, using rigorous structural-, damage-, and loss-analysis techniques, propagating all important sources of uncertainty, and avoiding reliance on expert opinion about building damageability.

- Vulnerability functions and HAZUS-compatible fragility functions. We set out to present results of the study in two forms: (1) the familiar seismic vulnerability function (damage factor as a function of shaking intensity) and (2) a form that can be used in FEMA's HAZUS software (fragility functions describing the probability of exceeding a few discrete damage states, along with some additional supporting data). We do not describe here the translation of vulnerability functions to HAZUS parameters; see Porter et al. (2002a) for that.

\section{USE OF VULNERABILITY FUNCTIONS IN SEISMIC RISK ANALYSIS}

\section{MEANING OF SEISMIC VULNERABILITY}

Seismic vulnerability, as used here, refers to a probabilistic relationship between the uncertain repair cost of a particular facility and the shaking intensity to which it is subjected in a single event. Figure 1 presents a stochastic seismic vulnerability function in schematic form, the development of which is a principal object of this study. It shows 


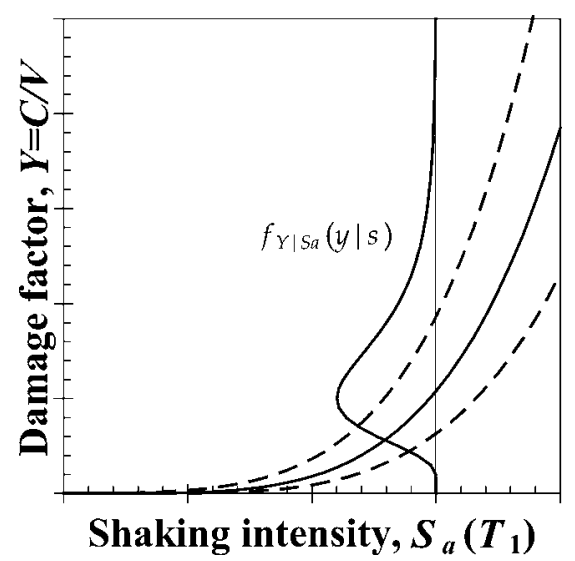

Figure 1. A seismic vulnerability function in schematic form. Three curves show the mean and \pm 1 standard deviation of repair cost as a fraction of replacement cost. Loss at any particular level of spectral acceleration is uncertain and has an associated probability distribution, $f_{Y \mid S a}(y \mid s)$.

uncertain repair cost as a fraction of replacement cost (referred to here as the damage factor, and denoted by $Y$ ) on the $y$-axis, and on the $x$-axis, an earthquake-shaking intensity measure $(I M)$, denoted here generically by $s$. In the present study, $s$ is chosen to be the damped elastic spectral acceleration at the facility's small-amplitude fundamental period, denoted by $S_{a}\left(T_{1}\right)$, although other $I M \mathrm{~s}$ can be used. The stochastic seismic vulnerability function is the conditional probability distribution of $Y$ given $S_{a}\left(T_{1}\right)=s$. The relationship between the mean value of damage factor and intensity is referred to here as the mean seismic vulnerability function, denoted here by $y(s)$.

\section{CALCULATION OF BENEFIT}

The expected value of economic benefit of a seismic retrofit or redesign measure (denoted here by $B$ ) can be calculated from the present value of the difference between the expected annualized repair cost before and after retrofit or redesign:

$$
B=\left(E A L-E A L_{r}\right)\left(\frac{1-\mathrm{e}^{-\rho t}}{\rho}\right)=\left(V \int_{0}^{\infty} y(s)\left|G^{\prime}(s)\right| d s-V_{r} \int_{0}^{\infty} y_{r}(s)\left|G_{r}^{\prime}(s)\right| d s\right)\left(\frac{1-\mathrm{e}^{-\rho t}}{\rho}\right)
$$

where $E A L$ denotes the expected annualized repair cost; $V$ refers to the replacement value of the facility: $\rho$ and $t$ denote the real discount rate and planning period, respectively; $y(s)$ refers to the mean seismic vulnerability function, i.e., the mean repair cost of the facility as a fraction of its replacement cost, given shaking intensity $s ; G(s)$ refers to the hazard function, i.e., the mean annual frequency of shaking exceeding intensity $s$; and $G^{\prime}(s)$ refers to its first derivative with respect to $s$. The subscript $r$ indicates these 
values after a retrofit or redesign. Since hazard depends on period, $G_{r}(s)$ may differ from $G(s)$.

In most practical circumstances, $y(s)$ and $G(s)$ are available only at discrete values of $s$. If we have $n+1$ values of $s$, at which both $y(s)$ and $G(s)$ are available, and we denote these values by $s_{i}, y_{i}$, and $G_{i}: i=0,1,2, \ldots n$, respectively, then $E A L$ in Equation 1 can be replaced, as shown in Porter et al. (2004), by

$$
\begin{aligned}
E A L & =V \sum_{i=1}^{n}\left(y_{i-1} G_{i-1}\left(1-\exp \left(m_{i} \Delta s_{i}\right)\right)-\frac{\Delta y_{i}}{\Delta s_{i}} G_{i-1}\left(\exp \left(m_{i} \Delta s_{i}\right)\left(\Delta s_{i}-\frac{1}{m_{i}}\right)+\frac{1}{m_{i}}\right)\right) \\
& =V \sum_{i=1}^{n}\left(y_{i-1} a_{i}-\Delta y_{i} b_{i}\right)
\end{aligned}
$$

where

$$
\begin{gathered}
\Delta s_{i}=s_{i}-s_{i-1} \quad \Delta y_{i}=y_{i}-y_{i-1} \quad m_{i}=\ln \left(G_{i} / G_{i-1}\right) / \Delta s_{i} \text { for } i=1,2, \ldots n \\
a_{i}=G_{i-1}\left(1-\exp \left(m_{i} \Delta s_{i}\right)\right) \quad b_{i}=\frac{G_{i-1}}{\Delta s_{i}}\left(\exp \left(m_{i} \Delta s_{i}\right)\left(\Delta s_{i}-\frac{1}{m_{i}}\right)+\frac{1}{m_{i}}\right)
\end{gathered}
$$

The post-retrofit or redesign $E A L$ is calculated similarly, except with $V, y(s)$, and $G(s)$ appropriate to the changed conditions. In some practical problems it may be desirable to calculate $E A L$ and $B$ for a location where site soil classification is uncertain (e.g., for a site whose location is inexactly known, such as by zip code), in which case Equation 2 can be replaced by

$$
E A L=\sum_{s c=1}^{N s c} p_{s c} V \int_{0}^{\infty} y(s)\left|G_{s c}^{\prime}(s)\right| d s=V \sum_{s c=1}^{N s c} \sum_{i=1}^{n} p_{s c}\left(y_{i-1} a_{i, s c}-\Delta y_{i} b_{i, s c}\right)
$$

and thus Equation 1 can be replaced by

$$
\begin{aligned}
B & =\sum_{s c=1}^{N s c} p_{s c} \cdot\left(V \int_{0}^{\infty} y(s)\left|G_{s c}^{\prime}(s)\right| d s-V_{r} \int_{0}^{\infty} y_{r}(s)\left|G_{r, s c}^{\prime}(s)\right| d s\right)\left(\frac{1-\mathrm{e}^{-\rho t}}{\rho}\right) \\
& =\left(V \sum_{s c=1}^{N s c} \sum_{i=1}^{n} p_{s c}\left(y_{i-1} a_{i, s c}-\Delta y_{i} b_{i, s c}\right)-V_{r} \sum_{s c=1}^{N s c} \sum_{i=1}^{n} p_{s c}\left(y_{i-1, r} a_{i, r, s c}-\Delta y_{i, r} b_{i, r, s c}\right)\right)\left(\frac{1-\mathrm{e}^{-\rho t}}{\rho}\right)
\end{aligned}
$$

where

$$
a_{i, s c}=G_{i-1, s c}\left(1-\exp \left(m_{i, s c} \Delta s_{i}\right)\right)
$$




$$
b_{i, s c}=\frac{G_{i-1, s c}}{\Delta s_{i}}\left(\exp \left(m_{i, s c} \Delta s_{i}\right)\left(\Delta s_{i}-\frac{1}{m_{i, s c}}\right)+\frac{1}{m_{i, s c}}\right)
$$

and where $N_{s c}$ refers to the number of possible site classifications; $p_{s c}$ denotes the probability of site classification $s c$; the subscript $s c$ on $G, G^{\prime}$, and $m$ indicate that they reflect the hazard for site class $s c$; and the subscript $r$ on $V, y, G, a$, and $b$ indicate that they reflect retrofitted or redesigned conditions.

Most of the parameters of Equations 1, 2, and 4 are relatively easy to acquire. The U.S. Geological Survey's estimates of seismic hazard $G(s)$ can be obtained from Frankel and Leyendecker's (2001) software. Electronic maps such as provided by Wills et al. (2000) present site classifications in GIS format. The values $V$ and $V_{r}$ can be estimated by standard construction cost-estimation techniques and approximated for many classes of facilities using publications such as RS Means (2001b). (In the present study, $V, V_{r}$, and other costs were estimated by a professional cost estimator.) The difficulty lies in estimating the seismic vulnerability functions. Three general approaches have been used to estimate $y(s)$ : empirical, analytical, and expert opinion, each with advantages and disadvantages.

\section{EMPIRICAL SEISMIC VULNERABILITY FUNCTIONS}

Empirical methods seek to acquire whole-building shaking intensity and loss information from past earthquakes for large numbers of individual buildings, and to regress the vulnerability functions directly from these data. Some historical efforts are documented by the U.S. Coast and Geodetic Survey (1969), Scholl et al. (1982), and ATC-38 (ATC 2001). Several proprietary models exist that use insurance loss experience, but these are not typically available to researchers. The difficulty is that nobody has collected data in enough detail about real houses and their actual earthquake shaking intensity and loss to distinguish the performance differences associated with detailed design or retrofit alternatives. See Porter (2002) for further discussion.

\section{EXPERT-OPINION SEISMIC VULNERABILITY FUNCTIONS}

The expert-opinion approach overcomes the difficulties of creating empirical seismic vulnerability functions, as experts can be asked to guess or judge the vulnerability of any type of facility, as long as they feel familiar enough with that facility type to offer a judgment. If they feel they lack adequate experience, experts typically refuse to offer judgment. An early application of expert opinion to earthquake vulnerability is found in Freeman (1932), who offers his judgment regarding future insurance losses by structure type and soil conditions. More recently, the authors of ATC-13 (ATC 1985) gathered the judgments of 70 earthquake engineering academics and practitioners, who estimated loss for 78 categories of buildings and other facilities as a function of shaking intensity. Typically between four and nine experts provide opinions on a given type of model structure type. 


\section{ANALYTICAL SEISMIC VULNERABILITY FUNCTIONS}

The need for analytical seismic vulnerability functions has been recognized at least since the early 1970s. Czarnecki (1973) appears to have been the first to formulate and illustrate a methodology to relate repair costs to shaking intensity using purely analytical means. His methodology called for a structural analysis to assess the member forces that an earthquake ground motion would produce in a building, followed by a loss analysis that related repair costs to member structural response. In the early 1980s, Scawthorn et al. (1981), Kustu et al. (1982), and others advanced the analytical approach, adding empirical information to the loss analysis stage, and explicitly treating uncertainty in component damage. The HAZUS methodology (NIBS and FEMA 1999) added pushover structural analysis and produced vulnerability models for a number of building categories. In developing the assembly-based vulnerability (ABV) framework for vulnerability assessment of individual buildings (as opposed to building categories), we employed nonlinear time-history structural analysis and added ground motion, mass, damping, and force-deformation behavior, along with greater detail regarding the facility components and component standardization (Porter et al. 2001, 2002a).

\section{METHODOLOGY}

$\mathrm{ABV}$ is employed here to calculate seismic vulnerability functions. The methodology meets the two main criteria set out by Hamburger and Moehle (2000) for a secondgeneration performance-based earthquake engineering (PBEE) methodology, namely, system-level performance evaluation (e.g., economic losses or repair duration) and rigorous propagation of all important sources of uncertainty. Furthermore, it avoids structural analysis simplifications and assumptions required for pushover-type analysis. It employs only experimental information, state-of-the-art structural- and damage-analysis principles, and well-established construction cost-estimation procedures. It does not rely on expert opinion or other difficult-to-verify methods. The study reported in Porter et al. (2002a) is its first application to woodframe buildings and to the estimation of the economic benefit of a common seismic retrofit measure for houses.

ABV has been presented in the past. See Porter et al. (2001, 2002a) for a detailed explanation of $\mathrm{ABV}$; only a summary is presented here. The methodology has five stages: facility definition, hazard analysis, structural analysis, damage analysis, and loss analysis, as illustrated in Figure 2. In brief, ABV is a simulation approach that pairs scaled ground-motion recordings with a stochastic structural model, performs nonlinear time-history structural analysis, simulates physical damage to individual assemblies based on laboratory or other empirical tests of assembly capacity, and calculates total repair costs using standard construction cost-estimation techniques, iterating to account for important sources of uncertainty. Figure 2 sketches the methodology used for calculating repair costs. For calculation of repair duration, see Beck et al. (1999) or Porter et al. (2001). For calculation of post-earthquake occupancy and life safety, see Porter et al. (2001).

Facility definition. To define the facility one must know its location (latitude and longitude) and design, including site soils, substructure, structural and nonstructural assemblies. One creates an inventory of the damageable assemblies and identify the engi- 


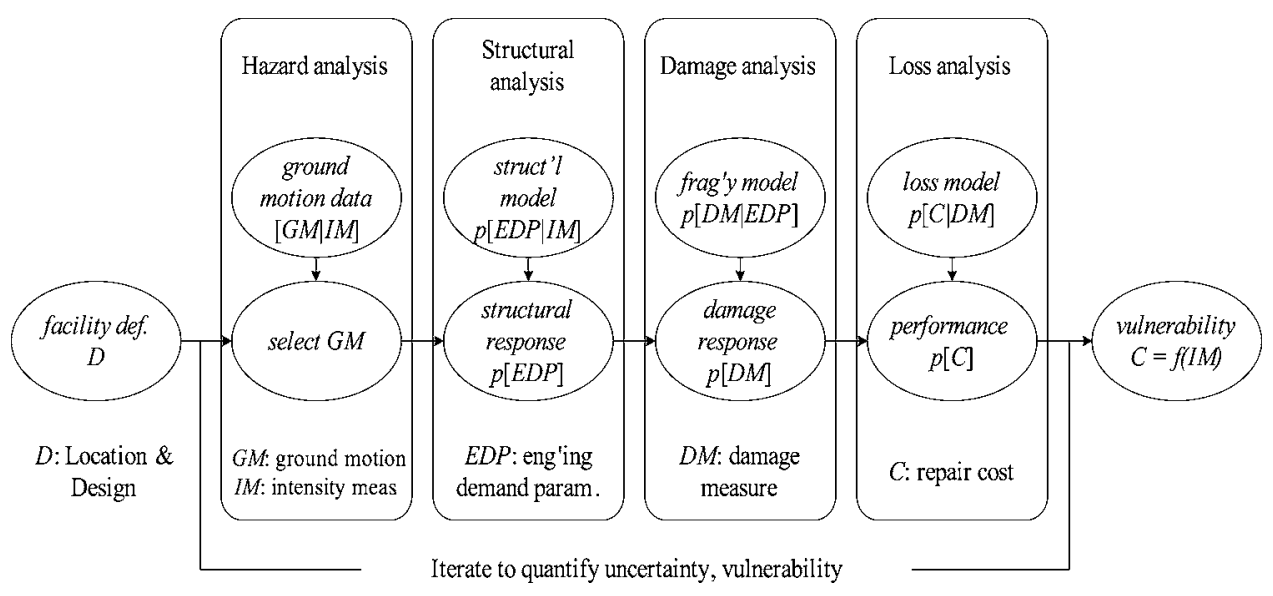

Figure 2. The assembly-based vulnerability methodology in schematic form.

neering demand parameter $(E D P)$ such as interstory drift ratio, member force, etc. that is the primary cause of damage to each assembly.

Ground-motion selection. In the following discussion, we assume that the facility stochastic vulnerability function is desired at $N_{S}$ levels of shaking intensity, i.e., $Y(s)$ for $s=s_{1}, s_{2}, \ldots s_{N s}$. For a given level of $s$, one selects a ground-motion time history and scales all of its accelerations by a constant to achieve an intensity value of interest. We use spectral acceleration at the facility's small-amplitude fundamental period of vibration $\left(S_{a}\left(T_{1}\right)\right)$ as the $I M$, and limit scaling of recorded ground-motion time histories to a factor of 2 to achieve the desired $I M$ level.

Structural analysis. In this stage, we create a stochastic structural model and, for each ground-motion time history, we perform a nonlinear time-history structural analysis to determine structural response, quantified via EDPs. By "stochastic structural model," we mean a model where masses, damping, and force-deformation behavior are uncertain, having prescribed probability distributions. We create a stochastic structural model by starting with a deterministic (best-estimate) structural model and multiplying all masses by a Gaussian variable $e_{M}$, multiplying viscous damping by a Gaussian variable $e_{\beta}$, and multiplying all strengths by a single Gaussian variable $e_{F D}$. Parameters of these probability distributions are discussed in the application later.

Damage analysis. For the damage and loss analyses, the facility is modeled as comprising a number of damageable assemblies. An assembly is a collection of one or more basic building components, assembled and in place, defined according to a standard taxonomic system such as the assembly-numbering system of RS Means (2001a), extended to account for details of seismic resistance, or the briefer and nonproprietary system defined in Porter (2005). In the damage analysis, one simulates damage to each damageable assembly via assembly fragility functions. It is assumed that after an assembly is subjected to a certain $E D P$, it will be in an uncertain damage state $D M$, indexed by 
$d m=0,1,2, \ldots N_{D M}$, where $d m=0$ indicates the undamaged state. We assume that the damage states can be sorted in increasing order, either because an assembly in damage state $d m=i+1$ must have passed through damage state $i$ already, or because the effort to restore an assembly from damage state $d m=i+1$ necessarily restores it from damage state $d m=i$. The threshold level of $E D P$ causing an assembly to reach or exceed damage state $d m$ is uncertain (we refer to it as the assembly's capacity to resist damage state $d m$ ), and is denoted by $X_{d m}$. The cumulative distribution function of capacity is denoted by $F_{X d m}(x)$. Then, given the response $x$ to which an assembly is subjected, the probability distribution of the damage state is

$$
F_{D M \mid E D P}(d m \mid x)=\sum_{\Delta=0}^{d m} P[D M=\Delta \mid E D P=x], \quad 0 \leqslant d m \leqslant N_{D M}
$$

where $F_{D M \mid E D P}(d m \mid x)$ denotes the cumulative probability distribution of damage state $D M$ evaluated at $d m$, given that $E D P=x$,

$$
\begin{aligned}
P[D M=d m \mid E D P=x] & =1-F_{X_{1}}(x) & & d m=0 \\
& =F_{X_{d m}}(x)-F_{X_{d m+1}}(x) & & 1 \leqslant d m<N_{D M} \\
& =F_{X_{N D M}}(x) & & d m=N_{D M}
\end{aligned}
$$

and $d m=0$ refers to the undamaged state. We take all capacities as lognormally distributed.

Note an important distinction between ABV and HAZUS (Kircher et al. 1997). In $\mathrm{ABV}$ each damageable assembly is modeled as having one or more possible damage states, each damage state having an uncertain capacity and an associated fragility function. In HAZUS the facility is modeled in three groups - drift-sensitive nonstructural components, acceleration-sensitive nonstructural components, and structural components - each group having a set of uncertain capacities and associated fragility functions. The levels of aggregation are very different.

Loss analysis. Given damage, assess loss as

$$
C_{T}=\left(1+C_{O P}\right)\left(\sum_{j} \sum_{d m} N_{j, d m} C_{j, d m}\right) C_{L} C_{I}
$$

where $C_{O P}$ refers to the (uncertain) contractor's overhead-and-profit factor; $N_{j, d m}$ refers to the number of assemblies of type $j$ in damage state $d m$ (determined in the damage analysis); $C_{j, d m}$ refers to the uncertain cost to restore one assembly of type $j$ from damage state $d m ; C_{L}$ refers to the location cost factor (local construction costs as a factor of those in the location for which the $C_{j, d m}$ are calculated); and $C_{I}$ refers to the inflation cost factor (construction costs in the year of interest as a factor of those in the year for which the $C_{j, d m}$ are calculated). We treat $C_{O P}$ as uncertain, with uniform distribution between 0.15 and 0.20 , and $C_{j, d m}$ as lognormal with mean and standard deviation varying by assembly type and damage state.

Tabulated values of $C_{L}$ and $C_{I}$ are commonly available, e.g., in RS Means (2001a). 
On average, $C_{L}$ is only of relatively modest importance, compared with hazard and other issues. Considering RS Means's (2001a) location factors, which provide an adjustment to construction costs by three-digit zip code zone, the mean location cost factor in California is 110 (the national average is 100) and the standard deviation is 4.5. That means that in about $68 \%$ of zip code zones, local construction costs are within $\pm 4 \%$ of the state average value; in $95 \%$ of zip code zones, the local construction costs are within $\pm 8 \%$ of the state average. Note also that, where local construction costs are particularly high or low, the savings in avoided future repair costs would be commensurately high or low and the benefit-cost ratios would be unchanged.

As an aside, note that we perform separate damage and loss analyses for at least two reasons: (1) to evaluate post-earthquake safety, operability or occupancy, which depend more on damage than economic loss, and (2) to compare modeled performance with performance of real buildings that have experienced an earthquake but where costs are unavailable.

Propagation of uncertainty. We have examined several ways to propagate uncertainty: Monte Carlo simulation, Latin Hypercube simulation, and moment matching (see Porter et al. 2001, Beck et al. 2002, and Ching et al. 2004, respectively). An alternative is to use first-order, second-moment analysis (FOSM), as described by Baker and Cornell (2003). We found that moment matching is more efficient and accurate for loss estimation than other methods, and unlike FOSM, estimates higher moments of loss than the variance (Ching et al., 2004). The study described here was performed before our recent study of moment matching. It employs Monte Carlo simulation, in which the foregoing steps (after facility definition) are repeated many times, each time sampling each uncertain variable once. This allows us to examine the probability distribution of total repair cost, compare with idealized distributions, and observe how uncertainty changes with increasing shaking intensity. The last item is valuable: uncertainty plays an important role in standard measures of seismic risk such as probable maximum loss (PML). It helps not to have to assume a probability distribution or guess at its parameters. For details, see Porter et al. (2002a).

\section{APPLICATION}

\section{INDEX BUILDINGS}

We applied ABV to four woodframe building designs, each with four or more variants reflecting different quality of construction, retrofit, or redesign, for a total of 19 buildings, which we refer to as variants. The designs, shown in Figure 3, are referred to as the small house, large house, townhouse, and apartment building. These hypothetical but fully designed buildings were created by a panel of architects and engineers (see Reitherman and Cobeen, 2003). Porter et al. (2002a) defined the quality levels.

We analyzed each building to produce a mean seismic vulnerability function, $y(s)$, as well as the distribution of the damage factor about $y(s)$. Viscous damping at small displacement was taken as $10 \%$ of critical, per Camelo et al.'s (2001) forced-vibration tests of a number of woodframe buildings. (The structural models separately reflect additional hysteretic damping at larger displacements, in the definition of the structural elements.) 


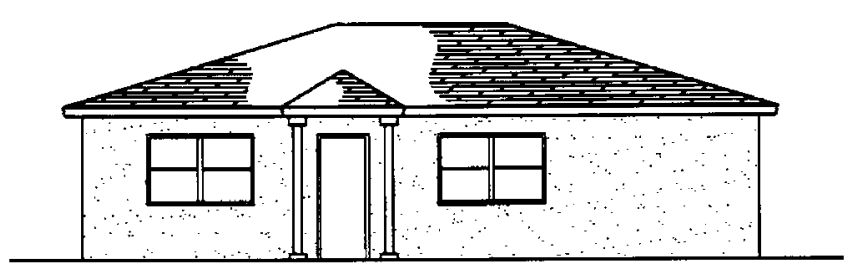

FRONT ELEVATON
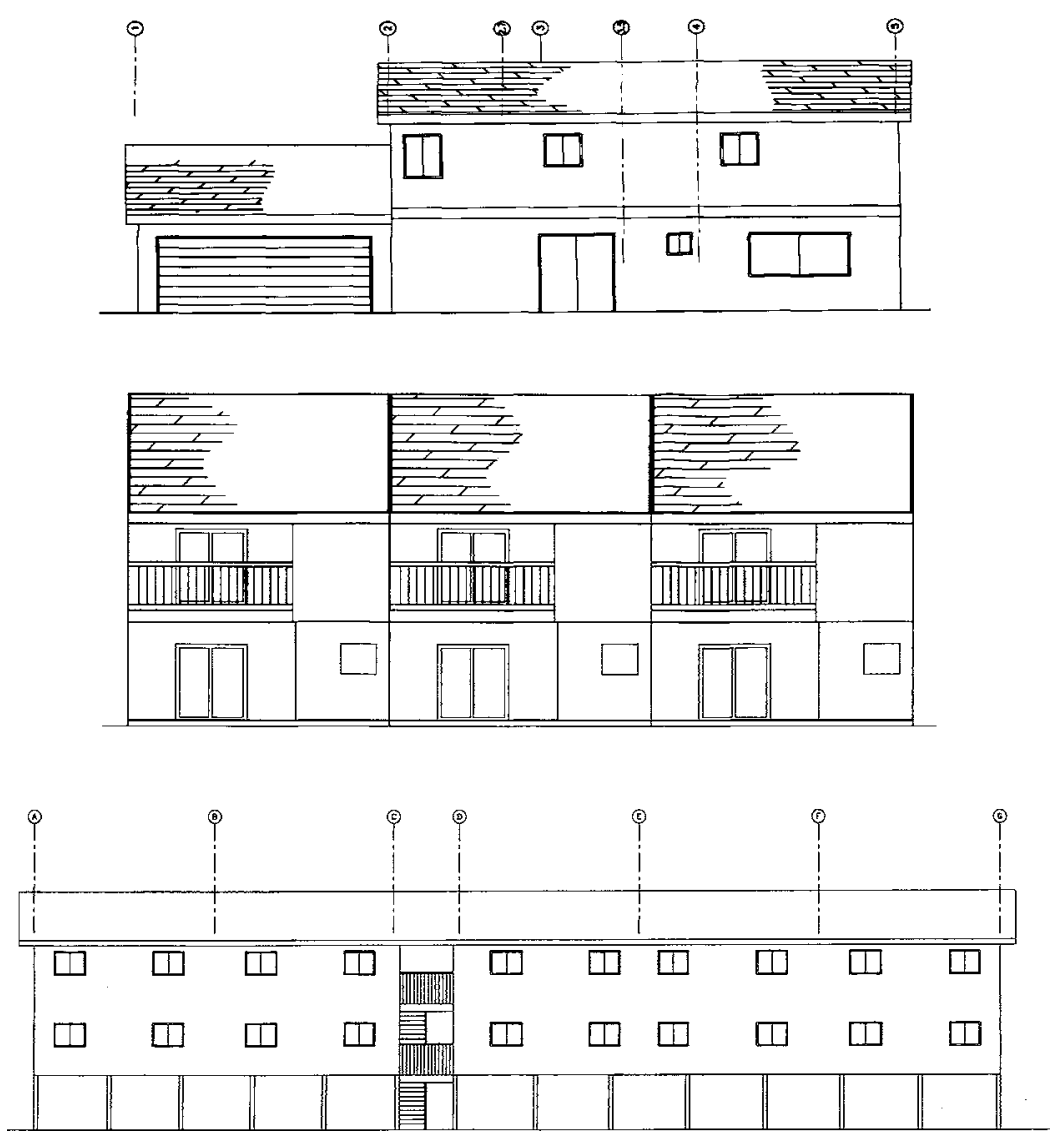

Figure 3. Index-building elevations (not to scale): (a) small house, (b) large house, (c) townhouse, and (d) apartment building.

We also used Camelo et al.'s (2001) regression analysis of $T_{1}$ versus building height to estimate small-amplitude fundamental periods for purposes of selecting and scaling ground-motion time histories. Camelo et al. (2001) produced these relationships for the CUREE-Caltech Woodframe Project through forced-vibration tests on a number of 
woodframe dwellings. Table 1 details the 19 variants and shows construction costs as estimated by a professional cost estimator. Table 2 gives dynamic characteristics.

Small House. This is a single-story, 1,200-sf single-family dwelling, with two bedrooms and one bathroom, with construction details appropriate to California housing built about 1950. Its walls are stucco-finished exterior, gypsum-wallboard interior finish, and no structural sheathing. It has a framed floor with perimeter cripple walls and postand-pier interior under-floor supports, on a level site. The design is based on prescriptive (conventional) construction, meaning that the design follows prescriptive rules of California building codes and common practice.

Large House. This is a hypothetical large single-family dwelling constructed in the late 1980s or early 1990s in California housing developments. It is a 2,420-sf two-story home with three bedrooms, 2.5 bathrooms, and an attached 400 -sf two-car garage. The site is level. The foundation is a slab on grade with spread footings. Walls have stucco exterior finish and gypsum wallboard interior. Many walls have plywood or oriented strandboard (OSB) sheathing. The design is engineered per the 1988 Uniform Building Code (ICBO 1988).

Townhouse. This is a hypothetical residential townhouse constructed in the early to mid-1990s as part of housing developments in California. Each of three units is a 2,000sf, two-story townhouse, with three bedrooms, two baths, and a 420-sf garage. It is on a level site with a slab on grade and spread footings. Exterior walls have stucco finish, many over plywood or OSB sheathing. Interior walls are finished with gypsum wallboard. The design is based on the 1988 Uniform Building Code (ICBO 1988), with some details of lateral resistance conforming to practice in Los Angeles since the 1994 Northridge earthquake.

Apartment Building. This building is a hypothetical multifamily apartment building constructed during the 1960s in California. A three-story, 13,700-sf apartment building with ten 850-sf units, it has two levels of residential space above ground-level tuckunder parking. The building is on a level site. The ground floor has a slab on grade with spread footings. Walls have stucco exterior finish, gypsum wallboard interior. Many but not all walls have plywood structural sheathing. The longitudinal front wall is open on the ground level to provide access to parking spaces, producing a soft-story effect that has proven to be hazardous in several recent earthquakes. The design is partially engineered in accordance with the 1964 Uniform Building Code (ICBO 1964). The in-plane shear capacity was designed per code requirements, but overturning was not considered or provided for in the detailing, as would be required with engineered construction in more recent years.

\section{ANALYSIS OF INDEX BUILDINGS}

Ground Motions. To reflect variability in ground motion, we drew on a set of horizontal-component pairs of 50 ground-motion time histories compiled by Somerville et al. (1997) for the SAC Steel project. The $I M$ of Figure 1 is the $10 \%$ damped elastic spectral acceleration at the building's small-amplitude fundamental period $T_{1}$, given in Table 2. We selected 20 ground-motion component pairs at random (without replace- 
Table 1. Index buildings and their variants. Replacements costs were estimated by a professional cost estimator using detailed construction drawings. Amounts are in 2002 US\$ and exclude land value. Costs are estimated to the nearest dollar but rounded in the table to two significant figures to reflect presumed accuracy. They reflect construction and permitting costs in the 904 zip code zone.

\begin{tabular}{|c|c|c|}
\hline Variant & Features & Cost \\
\hline \multicolumn{3}{|l|}{ Small house } \\
\hline Poor & $\begin{array}{l}\text { Poor stucco finish: low-strength, thin stucco; extensive degrada- } \\
\text { tion, poor furring and connection of mesh, poor anchorage; effect } \\
\text { is that strength is } 50 \text { to } 75 \% \text { relative to laboratory test results for } \\
\text { a high-quality specimen. Poor nailing of interior walls: many } \\
\text { missing, overdriven or common nails, resulting in } 75 \% \text { strength } \\
\text { of laboratory tests. Extra mass: } 3 \text { layers of roofing material in- } \\
\text { stead of } 2 \text {. }\end{array}$ & * \\
\hline Typical & $\begin{array}{l}\text { Average-quality stucco ( } 80 \% \text { strength relative to high-quality } \\
\text { laboratory tests). Good nailing of interior walls, few missing or } \\
\text { over-driven nails ( } 80 \text { to } 90 \% \text { strength). }\end{array}$ & $\$ 130,000$ \\
\hline Superior & $\begin{array}{l}\text { Reinforced concrete stem wall instead of stucco cripple wall. } \\
\text { Stucco: high strength, good thickness, good furring and connection } \\
\text { of mesh, no deterioration (strength same as high-quality laboratory } \\
\text { tests). Good nailing of interior walls (ditto). Light mass: } 1 \text { layer of } \\
\text { roofing instead of } 2 \text {. }\end{array}$ & $+3,600$ \\
\hline Retrofitted & $\begin{array}{l}\text { Retrofit typical-quality variant with new partial-length plywood } \\
\text { shear walls at cripple walls, and supplement existing bolts with } \\
\text { new bolts at new plywood shear walls, in compliance with } 1997 \\
U C B C \text { (ICBO 1997). }\end{array}$ & $+1,400$ \\
\hline \multicolumn{3}{|l|}{ Large house } \\
\hline Poor & $\begin{array}{l}\text { Poor nailing of shear walls and diaphragms }(80 \% \text { stiffness }) \text {. Poor } \\
\text { connections between structural elements }(80-85 \% \text { shear-wall } \\
\text { stiffness). Poor-quality stucco ( } 65-75 \% \text { strength). Poor nailing of } \\
\text { gypsum wallboard ( } 85 \% \text { strength). }\end{array}$ & $*$ \\
\hline Typical & $\begin{array}{l}\text { Average nailing of shear walls and diaphragms (95\% diaphragm } \\
\text { stiffness). Average connections between structural elements }(90- \\
95 \% \text { shear-wall stiffness). Average-quality stucco ( } 90 \% \text { strength). } \\
\text { Average nailing of gypsum wallboard ( } 90 \% \text { strength). }\end{array}$ & 220,000 \\
\hline Superior & $\begin{array}{l}\text { Good nailing of shear walls and diaphragms. Good connections } \\
\text { between structural elements. Good quality stucco. Good nailing of } \\
\text { gypsum wallboard. All components exhibit full strength, relative to } \\
\text { high-quality laboratory test specimens. }\end{array}$ & * \\
\hline Waist walls & $\begin{array}{l}\text { Same as typical quality, except structural sheathing added to } \\
\text { exterior walls above \& below openings in initial construction. }\end{array}$ & +260 \\
\hline Immed. Occ. & $\begin{array}{l}\text { Initial design to meet FEMA-273 (ATC 1997) IO performance in } \\
\text { BSE-1 event: thicker, high-grade sheathing, and heavier, closer } \\
\text { nailing }\end{array}$ & $+7,500$ \\
\hline Rigid diaphragm & $\begin{array}{l}\text { Initial design assumes rigid behavior of } 2^{\text {nd }} \text {-floor diaphragm, } \\
\text { flexible roof diaphragm }\end{array}$ & +270 \\
\hline \multicolumn{3}{|l|}{ Townhouse } \\
\hline Poor & Features similar to poor-quality large house. & * \\
\hline Typical & Features similar to typical-quality large house & 500,000 \\
\hline
\end{tabular}


Table 1. (cont.)

\begin{tabular}{|c|c|c|}
\hline Variant & Features & Cost \\
\hline Superior & Features similar to superior-quality large house & * \\
\hline Limit drift & $\begin{array}{l}\text { Initial design with thicker sheathing and foundation sills to } \\
\text { produce more uniform interstory drifts }\end{array}$ & $+1,700$ \\
\hline \multicolumn{3}{|l|}{ Apartment } \\
\hline Poor & $\begin{array}{l}\text { Features similar to poor-quality large house. Extra mass: } 3 \text { layers of } \\
\text { roofing material. }\end{array}$ & * \\
\hline Typical & $\begin{array}{l}\text { Features similar to typical-quality large house. Good connection of } \\
\text { pipe columns at parking. }\end{array}$ & 800,000 \\
\hline Superior & $\begin{array}{l}\text { Features similar to superior-quality large house. Light mass: } 1 \text { layer } \\
\text { of roofing instead of } 2 \text {. Superior connection of pipe columns: } \\
\text { bottom fixity, some moment resistance at top. }\end{array}$ & $*$ \\
\hline Steel frame & $\begin{array}{l}\text { Retrofit typical building with steel moment frames at garage } \\
\text { openings }\end{array}$ & $+29,000$ \\
\hline Shear wall & $\begin{array}{l}\text { Retrofit adds structural sheathing to center longitudinal wall at } \\
\text { ground floor }\end{array}$ & $+11,000$ \\
\hline
\end{tabular}

*It is problematic to assess the differential cost of poor- and superior-quality construction versus typical quality, and none is provided here (other than for the superior quality small house, where the figure reflects the different foundation type). Initial labor costs, construction inspection, and maintenance all play some role.

ment) for each $S_{a}$ from $0.1 \mathrm{~g}, 0.2 \mathrm{~g}$, etc., up to $2.0 \mathrm{~g}$, scaling amplitudes to the desired $S_{a}$, subject to three constraints: we preferred records whose amplitudes did not need to be scaled up or down by a factor of more than 2.0 to match the desired $S_{a}$; we preferred domestic (U.S.) records over foreign; and we preferred natural (recorded) ground motions over simulated ones. The scaling limitation was imposed on the advice of Campbell (2001). We imposed the other two preferences to avoid concerns about the appropriateness of the ground motions applied to the index buildings.

Structural Analysis. Isoda et al. (2001) created a best-estimate structural model for each of the 19 buildings, drawing on laboratory tests from the CUREE-Caltech Woodframe Project. They calculated shear-wall force-deformation characteristics using the CASHEW finite-element software developed by Folz and Filiatrault (2001). CASHEW requires as input the geometry of the framing elements, sheathing (e.g., plywood sheets), and connectors (nails and screws), as well as their force-deformation behavior.

Table 2. Fundamental period and damping ratios of index buildings

\begin{tabular}{lccc}
\hline \hline Index building (all variants) & Height & Period, sec. & Damping $^{*}$ \\
\hline Small house & $12 \mathrm{ft}$. & 0.13 & $10 \%$ \\
Large house & $20 \mathrm{ft}$. & 0.17 & $10 \%$ \\
Townhouse & $22 \mathrm{ft}$. & 0.18 & $10 \%$ \\
Apartment & $30 \mathrm{ft}$. & 0.21 & $10 \%$ \\
\hline \hline
\end{tabular}

\footnotetext{
${ }^{*}$ Viscous damping, in addition to hysteretic energy dissipation.
} 
CASHEW produces the parameters of an equivalent nonlinear spring, using the Stewart (1987) degrading-stiffness hysteresis model (including pinching; note that hysteretic energy dissipation is included in the models in addition to viscous damping). These springs were then used as elements in a whole-building structural model created for use in the 2-D nonlinear structural analysis package Ruaumoko (Carr 2001). For each index building, Isoda et al. (2001) created a so-called pancake model, in which building diaphragms are represented as a flat deformable plates ("pancakes") occupying the same plane, with shear walls represented by zero-height springs.

We used these best-estimate models to create a stochastic structural model of each building, creating 20 simulations of each building, with mass and viscous damping varying randomly. We took mass as the nominal amount times a lognormal error term with mean value of 1.05 and $10 \%$ coefficient of variation (COV), based on Ellingwood et al. (1980). We took viscous damping as lognormally distributed with a mean value of 0.10 and COV of $30 \%$, following Camelo et al. (2001). Subsequent study suggests that a more appropriate value would have been $40 \%$; see Porter et al. (2002b) for details. (In Beck et al. 2002 and Porter et al. 2004, our stochastic structural models also accounted for uncertainty in the force-deformation behavior of structural elements. Here we used the differences between the performance of the poor-quality, typical-quality, and superior-quality variants to examine the effect of strength variability.)

In each analysis, we randomly selected a ground-motion component pair, scaled it to the desired $S_{a}$ value, and randomly paired it with one of the 20 simulated structural models. We then performed a nonlinear time-history structural analysis and recorded the peak interstory drift ratios for each story and column line. These represent the EDPS of Figure 2. $E D P$ was calculated in each of 20 simulations at each of 20 levels of $S_{a}$ for each building.

Damage Analysis. The EDPs of the structural analysis were compared with the capacity of each assembly to determine the damage state of each assembly. We identified 13 distinct assembly types in the index buildings, each with up to four damage states, and developed fragility functions for each assembly type and damage state from various sources, notably tests of stucco walls by Chai et al. (2002); woodframe walls by Pardoen et al. (2000); gypsum wallboard partitions by McMullin and Merrick (2001); and plywood and oriented strandboard (OSB) sheathing with stucco finish by Gatto and Uang (2001). We also created theoretical glazing fragility functions, drawing on analytical procedures by Sucuoglu and Vallabhan (1997). See Porter et al. (2002a) Appendix E for details.

In addition to detailed physical damage by assembly, we modeled collapse for the small house and apartment building. Collapse was modeled as having occurred when cripple-wall drift (for the small house) or first-story drift (for the apartment building) on any column line exceeded an uncertain capacity that we modeled as lognormally distributed. Collapse capacity was simulated independently for each structural analysis by the inverse method; that is, for each structural analysis, we drew a sample $u$ from a uniform $(0,1)$ distribution and determine collapse capacity from 


$$
x=\exp \left(\Phi^{-1}(u) \cdot \beta+\ln \left(x_{m}\right)\right)
$$

where $\beta=0.1, x_{m}=2$ in. for the small house or 3 in. for the apartment building, and $\Phi^{-1}$ represents the inverse standard normal cumulative distribution function. The highquality variant of the small house was not modeled as susceptible to collapse because of its concrete stemwalls.

Loss Analysis. A professional cost estimator provided mean values of the cost to repair each assembly type and each damage state, considering construction costs in zip code zone 904 (within about 5\% of the average for the state of California, per RS Means [2001a]). The estimator was also asked for lower- and upper-bound estimates of unit cost $\left(10^{\text {th }}\right.$ and $90^{\text {th }}$ percentile values), but in our judgment these were too close to the mean, reflecting excessive confidence in the accuracy of the estimate; we increased the logarithmic standard deviations generally to between 0.2 and 0.3 . The effect is only to increase estimated uncertainty, and has no effect on the EAL and benefit-cost ratios presented later. We accounted for the cost to repaint rooms, hallways, and other lines of sight to reasonable uniform appearance, which generally can require repainting of undamaged surfaces. This expense, sometimes referred to as line-of-sight cost, sometimes referred to as reasonable uniform appearance, can be substantial, so it is important to consider it carefully.

We assumed the overhead-and-profit factor $C_{O P}$ to be uniformly distributed between 0.15 and 0.20 , per the cost estimator. For collapse, it was assumed that the apartment building would be a complete loss but that the small house could be jacked back into place, the cripple wall replaced with a braced cripple wall, and other necessary repairs performed. We modeled the cost to restore the small house as uniformly distributed between $\$ 33,000$ and $\$ 43,000$ plus overhead and profit, per the cost estimator. The location cost factor $C_{L}$ and inflation cost factor $C_{I}$ of Equation 8 are taken from RS Means (2001a).

\section{VULNERABILITY RESULTS}

\section{MEAN AND COEFFICIENT OF VARIATION OF THE CONDITIONAL DAMAGE FACTOR $Y(s)$}

The mean damage factor $y(s)$ and residual COV of $Y(s)$ are shown in Figure 4. The COV of damage factor conditioned on $s$, denoted here by $\delta_{Y \mid s}$, is defined as

$$
\delta_{Y \mid s} \equiv \sigma_{Y \mid s} / \mu_{Y \mid s}
$$

where $\sigma_{Y \mid s}$ denotes the standard deviation of the damage factor given $S_{a}=s$ and $\mu_{Y \mid s}$ denotes the mean. These $\delta_{Y \mid s}$ values are plotted against $\mu_{Y \mid s}$ rather than against $s$ because they correlate more strongly with the former than with the latter. The figure shows that the COV of the damage factor generally decreases with increasing mean damage factor. One interesting result is the plateau in the vulnerability functions for two variants of the small house above $0.7 \mathrm{~g}$, equivalent to about MMI X and above. Losses at these intensity levels are rare enough that they are fairly immaterial to expected annualized losses and therefore to benefit-cost ratios. We attribute the plateaus to cripple-wall damage act- 

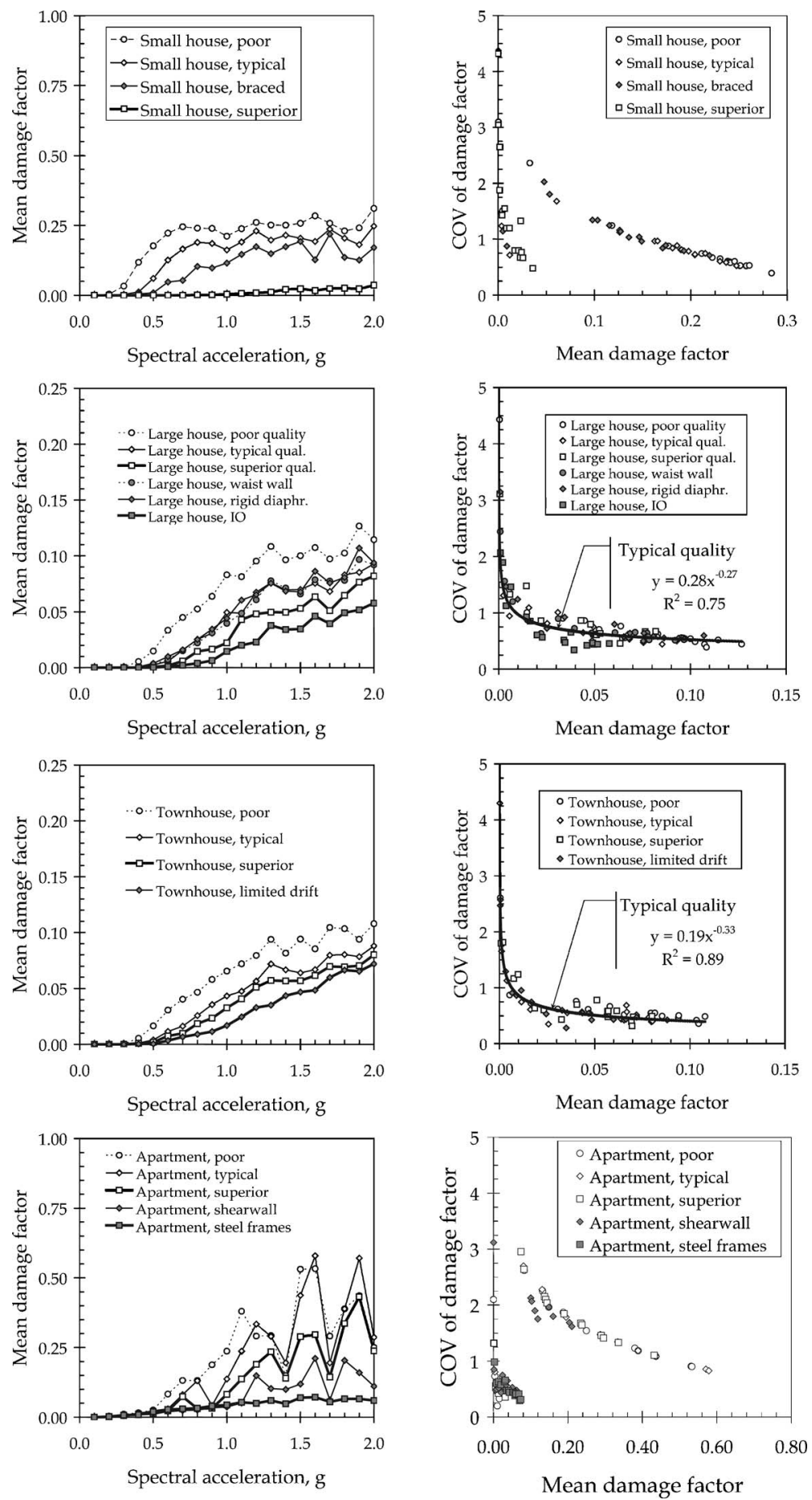

Figure 4. Mean seismic vulnerability functions and residual COV of seismic vulnerability. 
ing as a structural fuse, with repair costs limited by the cost to jack the building back into place.

\section{IDEALIZED DISTRIBUTION OF $Y(s)$}

To examine whether an idealized distribution reasonably fits the damage factor conditioned on $S_{a}$ (i.e., the form of $f_{Y \mid S a}(y \mid s)$ of Figure 1), we calculated for each simulation of loss a standardized damage factor in the log domain, denoted here by $\Psi_{\ln Y}$ and defined as

$$
\Psi_{\ln Y} \equiv\left(\ln Y-\mu_{\ln Y \mid s}\right) / \sigma_{\ln Y \mid s}
$$

where $\mu_{\ln Y \mid s}$ denotes the mean value of the natural logarithm of the damage factor given $S_{a}=S$, and $\sigma_{\ln Y \mid s}$ denotes its standard deviation. The cumulative distribution function of the samples $\Psi_{\ln Y}$ was then calculated and compared with the Gaussian distribution to see if the conditional damage factor can be approximated by a lognormal distribution.

Doing this for each typical-quality variant, limiting the data to $S_{a} \leqslant 1.0 \mathrm{~g}$, and performing a Kolmogorov-Smirnov goodness-of-fit test, we found that the lognormal adequately fits $Y(s)$ for the small house, townhouse, and apartment building at the $1 \%$ significance level, implying that at all intensity levels except rare, strong events, one can often approximate the damage factor as a lognormally distributed with a mean value approximated by a regression curve fit to $\mu_{Y \mid S a}$ and with COV as plotted in Figure 4 (see Porter et al. [2002a] for more detail). The probability of repair cost being less than or equal to some value $\psi$ is then given by

$$
P\left[Y \leqslant \psi \mid S_{a}=s\right]=\Phi\left(\frac{\ln (\psi / \hat{y}(s))}{\beta(s)}\right)
$$

where

$$
\begin{gathered}
\hat{y}(s)=y(s) / \sqrt{1+\delta_{Y \mid s}} \\
\beta(s)=\sqrt{\ln \left(1+\delta_{Y \mid s}^{2}\right)}
\end{gathered}
$$

\section{ASSEMBLY CONTRIBUTION TO COST}

We examined the loss data to determine which assemblies contribute most to repair cost. Ignoring collapse, we calculated the relative contribution to total repair cost from seven groups of assembly types: paint, stucco walls, exterior wood-sheathed shear walls, interior wood-sheathed shear walls, drywall, glazing, and water heater. An illustrative example is shown in Figure 5. (For other index buildings and variants, see Porter et al. 2002a.) The analysis shows a few interesting trends.

- Line-of-sight costs are substantial. Insurers typically pay to restore a damaged building to reasonable uniform appearance, meaning that if even a small portion of a wall is damaged and needs to be repainted, the entire room, hallway, or other line of sight is entirely repainted. Our analyses indicate that over a wide range of 


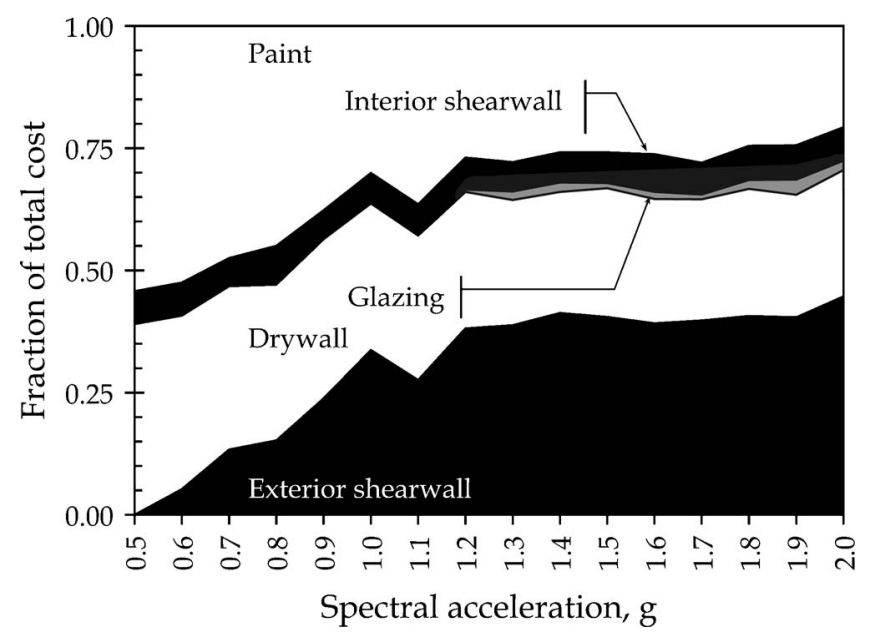

Figure 5. Assembly contribution to total repair cost, large house, typical quality.

intensity, painting contributes one-quarter to three-quarters of the total repair cost for these buildings. This suggests that models that do not account for lineof-sight costs can substantially underestimate repair costs.

- Drywall and exterior shear-wall costs are about equal. These assemblies contribute the bulk of the costs not attributable to painting. The small house is an exception, which can be explained by observing that most of the damage in the small house occurs at the cripple-wall level, where there is no gypsum wallboard. The other index buildings lack cripple walls. In them, the first-floor shear walls and drywall experience about equal repair costs.

- Glazing costs are minor. Repair of broken glass contributes less than $5 \%$ of the total repair costs; at moderate shaking intensity, glass contributes less than $1 \%$ of the total cost. In some of the plots, glazing costs are too minor to discern at this scale.

- Validation. We compared the theoretical results to historic earthquake experience data and to HAZUS estimates (Figure 6). For the former, we used published data from three earthquakes: 1994 Northridge, 1983 Coalinga, and 1971 San Fernando, by Steinbrugge and Algermissen (1990), Applied Technology Council (2001), Schierle (2000), and EQE and OES (1995). For the latter, we used Table 5 from Kircher et al. (1997). For plotting in Figure 6a, we recalculated our vulnerabilities in terms of the scaled PGAs of the ground motions used in the simulations, and converted from PGA to MMI using Wald et al. (1999). Figure 6 shows general agreement for the small house between theory and experience, and between our estimates and HAZUS's. For validation of other variants, see Porter et al. (2002). 

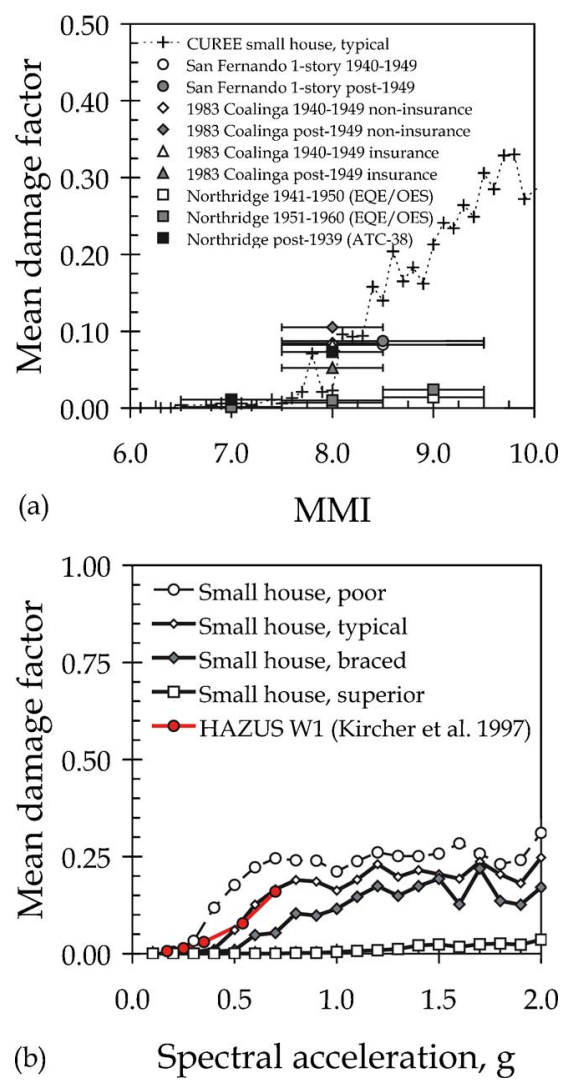

Figure 6. Small-house vulnerability functions versus (a) experience and (b) HAZUS.

\section{CALCULATION OF SEISMIC HAZARD}

We combined the vulnerability functions with seismic hazard to calculate $E A L$ and benefit of retrofit, redesign, and construction quality. We calculated mean seismic hazard at every zip code centroid in California as follows. We acquired Frankel and Leyendecker's (2001) gridded hazard data, which contain $G(s)$ at gridpoints of longitude $(\phi)$ and latitude $(\lambda)$ spaced at $\Delta \phi=\Delta \lambda=0.05^{\circ}$ throughout California for $s=5 \%$ damped elastic spectral acceleration at periods of $T=0,0.1,0.2,0.3,0.5,1.0$, and $2.0 \mathrm{sec}$, for NEHRP site classification at the BC boundary. For purposes of interpolating $G(s)$ between any four adjacent gridpoints $\left\{\left(\phi_{1}, \lambda_{1}\right),\left(\phi_{1}+\Delta \phi, \lambda_{1}\right),\left(\phi_{1}, \lambda_{1}+\Delta \lambda\right)\right.$, and $\left.\left(\phi_{1}+\Delta \phi, \lambda_{1}+\Delta \lambda\right)\right\}$ we transformed the $(\phi, \lambda, G(s))$ coordinate system to an $(x, y, z)$ system where $x=(\phi$ $\left.-\phi_{1}\right) /(\Delta \phi), y=\left(\lambda-\lambda_{1}\right) /(\Delta \lambda)$, and $z=G(s)$. We assumed that between any four such gridpoints, $G(s)=a_{1} x^{2}+a_{2} y^{2}+a_{3} x y+a_{4}$. One can show that $a_{1}=\left(z_{2}-z_{1}\right), a_{2}=\left(z_{3}-z_{1}\right)$, $a_{3}=\left(z_{4}-z_{3}-z_{2}+z_{1}\right)$, and $a_{4}=z_{1}$, where $z_{1}, z_{2}, z_{3}$, and $z_{4}$ correspond to $G(s)$ at the $(x, y)$ points $(0,0),(1,0),(0,1)$, and $(1,1)$, respectively.

We used this transformation and interpolation scheme to estimate $G(s)$ at the cen- 
Table 3. Damping factor $\mathrm{Fb} 10 \%$. The table shows moments of the ratio of $10 \%$ to $5 \%$ damped $\mathrm{Sa}$, from 100 motions provided by Somerville et al. (1997)

\begin{tabular}{ccccccc}
\hline \hline$T$, sec & 0.1 & 0.2 & 0.3 & 0.5 & 1.0 & 2.0 \\
\hline$\mu_{F b 10 \%}$ & 0.891 & 0.831 & 0.808 & 0.811 & 0.835 & 0.863 \\
$\sigma_{F b 10 \%}$ & 0.082 & 0.086 & 0.083 & 0.072 & 0.076 & 0.083 \\
\hline \hline
\end{tabular}

troid of each thematic zip code in California for each period $T$, for NEHRP site classification at the BC boundary. Zip code centroids were taken from GDT (2000b). We used Bispec (Hachem 2000) to analyze the ground-motion time histories provided by Somerville et al. (1997), calculating $S_{a}(T)$ at each $T$ and at damping ratios of 5\% and $10 \%$. We refer to the ratio of the $10 \%$ damped to $5 \%$ damped $S_{a}$ as the damping factor, $F_{b 10 \%}$. Using these data, we calculated the mean and standard deviation of $F_{b 10 \%}$, denoted here by $\mu_{F b 10 \%}$ and $\sigma_{F b 10 \%}$, respectively, and shown in Table 3. We calculated the area fraction of each California zip code that has NEHRP site classification A, AB, B, BC, C, CD, D, $\mathrm{DE}$, and $\mathrm{E}$. This fraction is later used as $p_{s c}$ of Equation 4. Site classifications were taken from Wills et al. (2000). Zip code boundaries were taken from GDT (2000a). The intersection was calculated using ArcView8 (ESRI 2001).

We calculated $G(s)$ at each zip code, each $T$, both $5 \%$ and $10 \%$ damping ratios, and all the site categories present in each zip code. For zip code $z$, site category $s c$, period $t$, and damping ratio $b$, we calculated $G(s \mid z, s c, t, b)=G\left(F_{s} F_{b} s \mid z, s c=\mathrm{BC}, t, 5 \%\right)$. Here, $F_{s}$ is the appropriate site-classification factor $F_{a}$ or $F_{v}$ as a fraction of $F_{a}$ or $F_{v}$ for site classification BC from ICC (2000): $F_{s}=F_{a}$ for $T \in\{0.1,0.2,0.3 \mathrm{sec}\} ; F_{s}=F_{v}$ for $T$ $\in\{1.0,2.0 \mathrm{sec}\}$. For $T=0.5 \mathrm{sec}, F_{s}=F_{a}$ for site classes A through $\mathrm{BC}$, and $F_{s}=F_{v}$ for site classes $\mathrm{C}$ through $\mathrm{E}$. The factor $F_{b}$ is the mean damping factor (unity for $5 \%$ damping).

For each zip code, site class, period, and damping ratio, we interpolated $G(s)$ between values of $s$ resulting from the previous step to achieve $G(s)$ at a standard set of $s$ :

$$
G(s)=\exp \left(\ln G\left(s_{0}\right)+\ln \left(\frac{G\left(s_{1}\right)}{G\left(s_{0}\right)}\right) \frac{\left(s-s_{0}\right)}{\left(s_{1}-s_{0}\right)}\right): s \in\{0.1,0.2, \ldots 2.0 g\}, \quad s_{0} \leqslant s<s_{1}
$$

where $s_{0}$ and $s_{1}$ are values of $s$ whose $G(s)$ are available from the previous step. Finally, for each zip code, site class, $s \in\{0.1,0.2, \ldots 2.0 \mathrm{~g}\}$, and for $10 \%$ damping, we interpolated between available $G(s, T)$ curves produced in the previous step to calculate hazard at the index-building periods shown in Table 2 as

$$
G(s, T)=\exp \left(\ln G\left(s, T_{0}\right)+\ln \left(\frac{G\left(s, T_{1}\right)}{G\left(s, T_{0}\right)}\right) \frac{\ln \left(T / T_{0}\right)}{\ln \left(T_{1} / T_{0}\right)}\right)
$$




\section{CALCULATION OF BENEFITS OF SEISMIC RETROFIT}

What if the owner of one of these particular buildings in a particular zip code made one of the changes examined here, such as seismic retrofit of the small house, abovecode design of the townhouse, or higher construction quality of the apartment building? What would be the economic benefit to the owner? (We do not consider here the benefit to society of a probabilistic mix of various buildings, but rather these particular buildings and these particular mitigation measures in zip codes throughout California.) We applied Equation 3 to each index building and variant to determine its expected annualized repair cost on a zip code basis, and calculated the benefit by Equation 4 for each retrofit and redesign measure. We used the Wills et al. (2000) and GDT (2000a) maps to determine $p_{s c}$, the professional cost estimator's values for $V$, the ABV models for $y(s)$, and Frankel and Leyendecker's (2001) data (manipulated as described above) for $G(s)$.

\section{COST-EFFECTIVE RETROFITS AND REDESIGN MEASURES}

There are several ways to depict the cost-effectiveness of a capital investment for both public-sector and private-sector decision-makers. A common engineering economics text (Newnan 1983) details rate-of-return analysis, incremental analysis, benefit-cost ratio analysis, and others. Following the example of FEMA 227 (VSP Associates 1992), which FEMA intended for use "by community officials, analysts, and practitioners to help evaluate the economic benefits and costs of seismic rehabilitation of existing hazardous buildings," benefit-cost ratio analysis is used here to measure cost-effectiveness.

Figure 7 shows the calculated benefit and benefit-cost ratio (BCR) of the seismic retrofit of the small house: supplementing existing foundation bolts, adding structural sheathing to unbraced cripple walls, and strapping the water heater to the frame. The figure reflects a real (after-inflation) discount rate of $3 \%{ }^{1}$ and a planning period of $30 \mathrm{yr}$. The retrofit is cost-effective in half of California zip codes (781 of 1,653 thematic zip codes). None of the redesign measures for the large house is estimated to be costeffective in California. Figure 8a shows the benefit of above-code (limited-drift) design of the townhouse in the San Francisco Bay area. It is cost-effective in 300 zip codes statewide, primarily in the highly seismic coastal regions, with a present value of benefit as high as $\$ 8,000$ per building. (Again, variations in local construction costs are accounted for using the location factors tabulated in RS Means [2001a].) Both mitigation measures for the apartment building are estimated to be cost-effective in various California locations; maps are omitted because of space constraints. In summary, four of the seven retrofit or redesign measures can be cost-effective.

\section{BENEFIT OF CONSTRUCTION QUALITY}

It may be that architects, building inspectors, and others involved in the initial construction of a building could enhance its quality through more frequent inspection. It is problematic to estimate the up-front cost of such enhanced construction quality, but it is interesting to examine its benefits in terms of reduced future earthquake repair costs.

\footnotetext{
${ }^{1} 6 \%$ mortgage interest rate (California Department of Finance 2004) less 3\% inflation (Bureau of Labor Statistics 2004).
} 

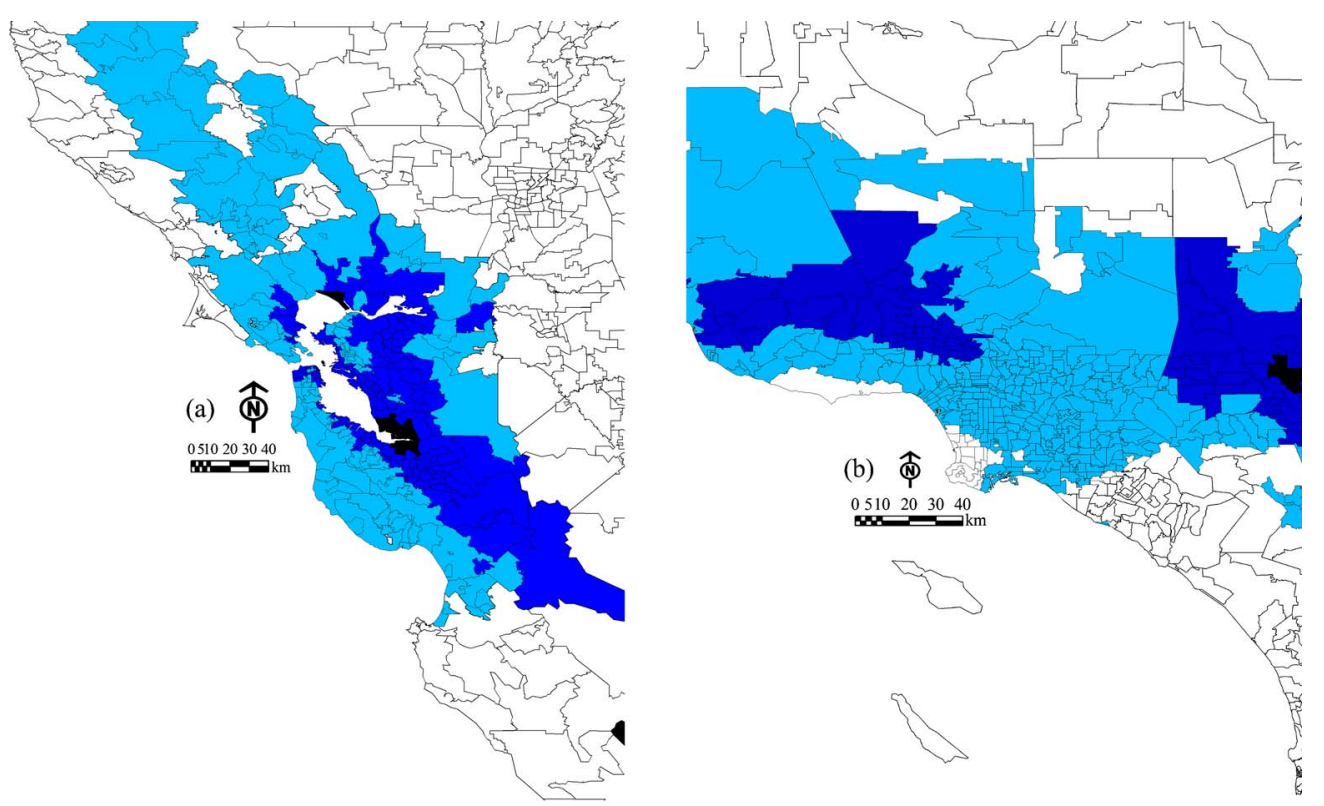

(b) 雷
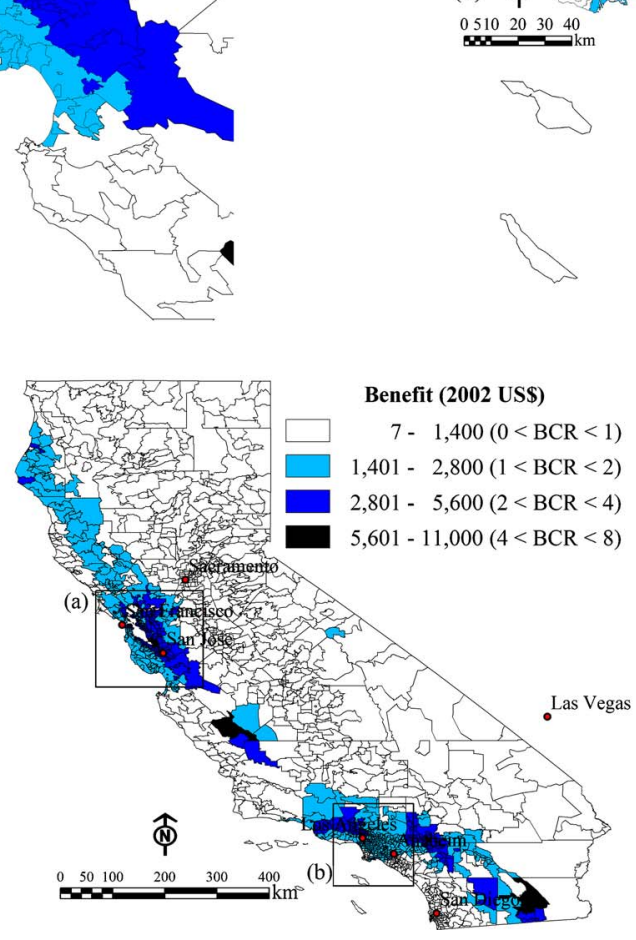

Figure 7. Benefit of retrofitting small house by supplementing existing foundation bolts, adding structural sheathing to cripple walls, and strapping the water heater to the building frame.

Applying Equation 4 to different quality levels of the same index building, we find that construction quality makes an important impact on earthquake losses:

- For the small house, the median benefit of typical-quality construction of the small house, compared with the poor-quality variant, is $\$ 3,000$. (That is, the typical-quality variant is expected to experience at least $\$ 3,000$ lower repair costs than the poor-quality variant in half of California zip codes). The median benefit 

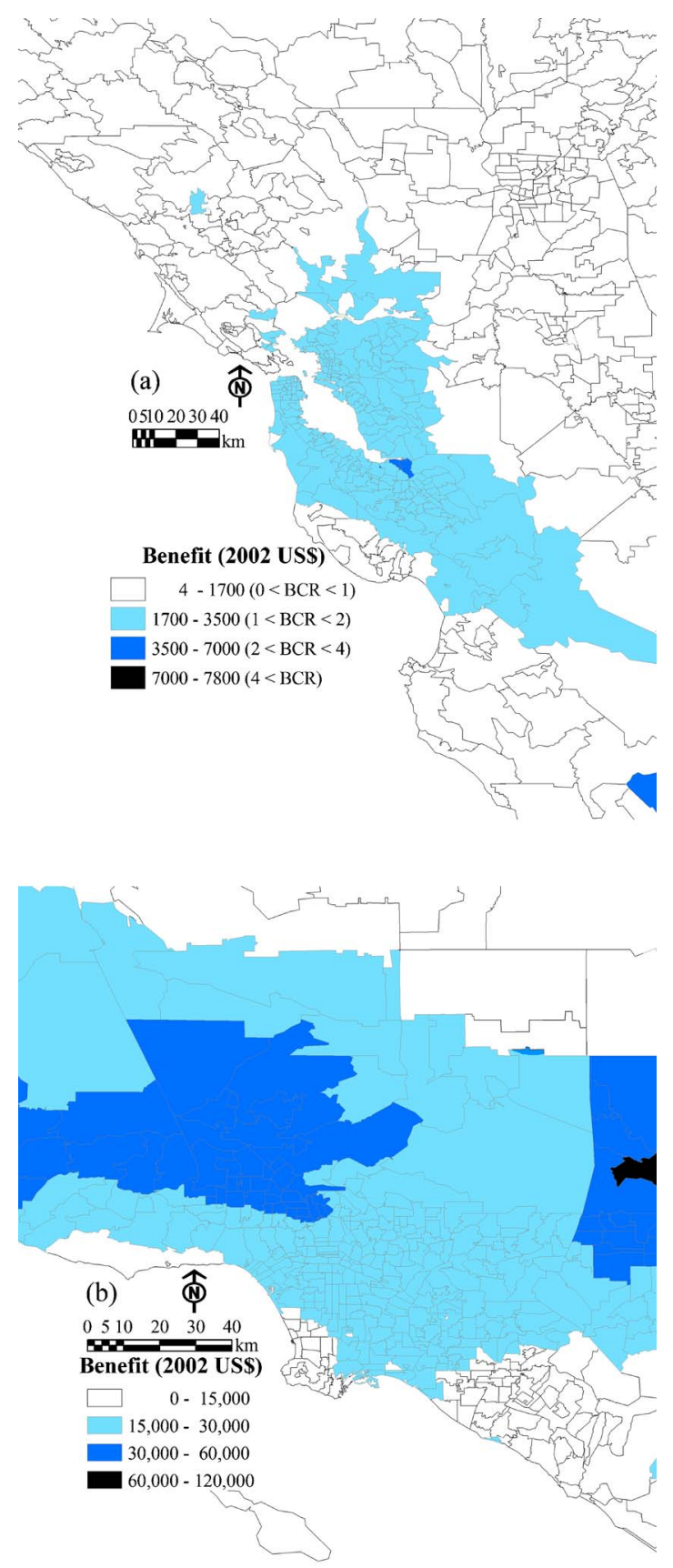

\)

Figure 8. (a) Benefit of designing the townhouse for above-code (limited-drift) performance in the San Francisco Bay area, and (b) benefit of ensuring superior-quality construction of the apartment building in the Los Angeles area, relative to poor quality. 
of the superior versus poor quality is $\$ 5,400$. (Note that the superior variant has concrete stemwalls rather than cripple walls.)

- For the large house, the median savings associated with the typical and superiorquality variants are $\$ 770$ and $\$ 970$, respectively.

- For the townhouse, the savings for the typical-quality and high-quality variants are $\$ 1,400$ and $\$ 1,700$, respectively.

- For the apartment building, the median savings are $\$ 8,700$ and $\$ 13,000$, respectively, for the typical- and superior-quality variants; the maximum saving is $\$ 120,000$ per building. Figure $8 \mathrm{~b}$ shows the benefit of superior versus poor construction quality for the apartment building in the Los Angeles area.

\section{LOSSES OTHER THAN REPAIR COSTS ARE IGNORED}

The BCRs shown here are based solely on repair costs under normal (noncatastrophic) conditions. If we accounted for demand surge (the potential for repair costs to be greater after a major catastrophe), content loss, loss of use, human injuries, etc., BCRs would be much higher. Including these additional benefits would be a simple extension of the methodology presented here, assuming that the required fragility and other data are available.

\section{CONCLUSIONS}

We present probabilistic seismic vulnerability functions for 19 fully designed woodframe dwellings. We employed laboratory tests and analytical tools developed under the CUREE-Caltech Woodframe Project, and we rigorously propagated important sources of uncertainty. We used dynamic time-history structural analyses, clearly accounted for repair costs, including line-of-sight costs, and avoided reliance on expert opinion. Each vulnerability function includes information on the repair-cost distribution conditioned on $S_{a}$. Using soil maps produced by the California Geological Survey and hazard data by the U.S. Geological Survey, we calculated the expected annualized loss for each building, the benefit-cost ratio for seven detailed retrofit and redesign measures, and the benefit of higher construction quality, all on a zip code basis.

Four of the retrofit and redesign measures are estimated to be cost-effective in various locations throughout California-generally near faults and on soft soil, as expected. When examining the benefit of higher-quality construction, we found that the savings in terms of reduced seismic risk can be substantial, with median savings on the order of $\$ 1,000$ to $\$ 10,000$ over $30 \mathrm{yr}$, suggesting a quantitative argument for frequent construction inspection. These results ignore benefits such as reduced content damage, reduced loss of use, and human injuries avoided. Were these benefits included, benefit-cost ratios would be substantially greater. These benefits are easily included in the methodology, given the appropriate data. The results also ignore demand surge. Including demand surge would also increase estimated benefits. The data presented here can be used to inform risk-management decisions by homeowners, engineers, and public officials. Homeowners can use this information to decide if retrofit is likely to be worth the expense. Engineers can use the data in the development of code requirements. Public officials can 
use the data to target particular dwelling types and geographic locations for public awareness programs that promote retrofit where it is likely to be cost-effective.

\section{ACKNOWLEDGMENTS}

The research was performed with funding by the Federal Emergency Management Agency, the California Governor's Office of Emergency Services, and Caltech's George W. Housner Fund. Tom Boyd, Kelly Cobeen, Robert Reitherman, James Russell, and Hope Seligson provided valuable advice and assistance throughout the project. The research also greatly benefited from the help of Vanessa Camello, Ken Campbell, Ken Compton, André Filiatrault, Bryan Folz, Bill Graf, Hiroshi Isoda, David Johnson, David McCormick, Goetz Schierle, Ed Sylvis, Tom Tobin, and Ray Young. John Hall was the overall PI of the CUREE-Caltech Woodframe Project. The contributions of all these individuals and organizations are gratefully acknowledged.

\section{REFERENCES}

Applied Technology Council (ATC), 1985. ATC-13, Earthquake Damage Evaluation Data for California, Redwood City, CA, 492 pp.

ATC, 1997. NEHRP Guidelines for the Seismic Rehabilitation of Buildings, prepared for the Building Seismic Safety Council, published by the Federal Emergency Management Agency, FEMA-273, Washington, D.C., 386 pp.

ATC, 2001. ATC-38, Database on the Performance of Structures Near Strong-Motion Recordings: 1994 Northridge, California, Earthquake, Redwood City, CA.

Baker, J. W., and Cornell, C. A., 2003. Uncertainty Specification and Propagation for Loss Estimation Using FOSM Methods, PEER Report 2003/07, Pacific Earthquake Engineering Research Center, Richmond, CA.

Beck, J. L., Kiremidjian, A., Wilkie, S., Mason, A., Salmon, T., Goltz, J., Olson, R., Workman, J., Irfanoglu, A., and Porter, K., 1999. Decision Support Tools for Earthquake Recovery of Businesses, Final Report, CUREE-Kajima Joint Research Program Phase III, CUREE, Richmond, CA.

Beck, J. L., Porter, K. A., Shaikhutdinov, R., Au, S. K., Mizukoshi, K., Miyamura, M., Ishida, H., Moroi, T., Tsukada, Y., and Masuda, M., 2002. Impact of Seismic Risk on Lifetime Property Values, CUREE, Richmond, CA. http://resolver.caltech.edu/caltechEERL:2002.EERL2002-04

Bureau of Labor Statistics, 2004. Consumer Price Index Summary, Washington, D.C.

California Department of Finance, 2004. California Economic Indicators, Jan-Feb 2004, Sacramento, CA.

Camelo, V. S., Beck, J. L., and Hall, J. F., 2001. Dynamic Characteristics of Woodframe Structures, CUREE, Richmond, CA, 68 pp.

Campbell, K. W., 2001. Personal communication.

Carr, A. J., 2001. Ruaumoko 2-D, University of Canterbury, Christchurch, New Zealand.

Chai, Y. H., Hutchinson, T. C., and Vukazich, S. M., 2002. Seismic Behavior of Level and Stepped Cripple Walls, Task 1-4-3 Final Report, CUREE, Richmond, CA, 158 pp. 
Ching, J. Y., Porter, K. A., and Beck, J. L., 2004. Uncertainty Propagation and Feature Selection for Loss Estimation in Performance-Based Earthquake Engineering, EERL Report No. 2004-02, California Institute of Technology, Pasadena, CA.

CUREE (Consortium of Universities for Research in Earthquake Engineering), 2003. The CUREE-Caltech Woodframe Project, Richmond, CA.

Czarnecki, R. M., 1973. Earthquake Damage to Tall Buildings, Structures Publication 359, Massachusetts Institute of Technology, Cambridge, MA, $125 \mathrm{pp}$.

Ellingwood, B., Galambos, T. V., MacGregor, J. G., and Cornell, C. A., 1980. Development of a Probability-Based Load Criterion for American National Standard A58, National Bureau of Standards, Washington, D.C., 222 pp.

EQE International and the Governor's Office of Emergency Services (EQE/OES), 1995. Northridge Earthquake of Jan. 17, 1994: Report of Data Collection and Analysis, EQE International, Irvine, CA.

ESRI, Inc., 2001. ArcView8, Redlands, CA.

Folz, B., and Filiatrault, A., 2001. Cyclic analysis of wood shearwalls, J. Struct. Eng. 127 (4).

Frankel, A., and Leyendecker, E. V., 2001. Uniform Hazard Response Spectra and Seismic Hazard Curves for the United States, CD-ROM, U.S. Geological Survey, Menlo Park, CA.

Freeman, J. R., 1932. Earthquake Damage and Earthquake Insurance, McGraw-Hill, New York, NY.

Gatto, K., and Uang, C. M., 2001. Cyclic Response of Woodframe Shearwalls: Loading Protocol and Rate of Loading Effects, SSRP-2001/06, Department of Structural Engineering, U.C. San Diego, La Jolla, CA.

Geographic Data Technology, Inc. (GDT), 2000a. California ZIP Code Areas, ESRI Inc., Redlands, CA.

Geographic Data Technology (GDT), 2000b. U.S. ZIP Code Points, ESRI Inc., Redlands, CA.

Hachem, M. M., 2000. BiSpec Version 1.1.2, University of California, Berkeley, CA.

Hamburger, R. O., and Moehle, J. P., 2000. State of performance-based engineering in the United States, 2nd U.S.-Japan Workshop on Performance-Based Earthquake Engineering Methodology for Reinforced Concrete Building Structures, Sapporo, Japan, September.

International Code Council (ICC), 2000. International Building Code 2000, Whittier, CA.

International Conference of Building Officials (ICBO), (various dates). Uniform Building Code, Whittier, CA.

International Conference of Building Officials (ICBO), 1997. Uniform Code for Building Conservation, Whittier, CA.

Isoda, H., Folz, B., and Filiatrault, A., 2001. Seismic Modeling of Index Woodframe Buildings on Research Task 1.5.4., CUREE, Richmond, CA, 144 pp.

Kircher, C. A., Nassar, A. A., Kustu, O., and Holmes, W. T., 1997. Development of building damage functions for earthquake loss estimation, Earthquake Spectra 13 (4), 663-682.

Kustu, O., Miller, D. D., and Brokken, S. T., 1982. Development of Damage Functions for Highrise Building Components, for U.S. Dept of Energy, URS/John A. Blume \& Assoc, San Francisco, CA. 
McMullin, K., and Merrick, D., 2001. Seismic Performance of Gypsum Walls-Experimental Test Program, CUREE, Richmond, CA.

National Institute of Building Sciences (NIST) and Federal Emergency Management Agency (FEMA), 1999. HAZUS Earthquake Loss Estimation Methodology: Technical Manual, Washington, D.C.

Newnan, D. G., 1983. Engineering Economic Analysis, Engineering Press Inc., Sacramento, CA.

Pardoen, G. C., Kazanjy, R. P., Freund, E., Hamilton, C. H., Larsen, D., Shah, N., and Smith, A., 2000. Results from the city of Los Angeles-UC Irvine shear wall test program, 6th World Conference on Timber Engineering.

Porter, K. A., 2002. Learning from earthquakes: A survey of surveys, EERI Invitational Workshop: an Action Plan to Develop Earthquake Damage and Loss Data Protocols, September 19-20, 2002, Pasadena, Calif., Earthquake Engineering Research Institute, Oakland, CA.

Porter, K. A., 2005. A Taxonomy of Building Components for Performancebased Earthquake Engineering, PEER Report 2005/03, Pacific Earthquake Engineering Research Center, University of California, Berkeley, $60 \mathrm{pp}$.

Porter, K. A., Beck, J. L., Seligson, H. A., Scawthorn, C. R., Tobin, L. T., and Boyd, T., 2002a. Improving Loss Estimation for Woodframe Buildings, Publication W-18, CUREE, Richmond, CA, $136 \mathrm{pp}$.

Porter, K. A., Beck, J. L., and Shaikhutdinov, R. V., 2002b. Sensitivity of building loss estimates to major uncertain variables, Earthquake Spectra 18 (4), 719-743.

Porter, K. A., Beck, J. L., and Shaikhutdinov, R. V., 2004, Simplified estimation of economic seismic risk for buildings, Earthquake Spectra 20 (4), 1239-1263.

Porter, K. A., Kiremidjian, A. S., and LeGrue, J. S., 2001, Assembly-based vulnerability of buildings and its use in performance evaluation, Earthquake Spectra 17 (2), 291-312.

Reitherman, R., and Cobeen, K., 2003. Design Documentation of Woodframe Project Index Buildings, Publication W-29, CUREE, Richmond, CA, 258 pp.

RS Means, 2001a. Assemblies Cost Data, 26th Edition, Kingston, MA.

RS Means, 2001b. Means Square Foot Costs 2001 Book, 22nd Edition, Kingston, MA.

Scawthorn, C. R., Iemura, H., and Yamada, Y., 1981. Seismic damage estimation for low- and mid-rise buildings in Japan, Earthquake Eng. Struct. Dyn. 9, 93-115.

Schierle, G. G., 2000. Northridge Earthquake Field Investigations: Statistical Analysis of Woodframe Damage, Publication W-02, CUREE, Richmond, CA.

Scholl, R. E., Kustu, O., Perry, C. L., and Zanetti, J. M., 1982. Seismic Damage Assessment for High-Rise Buildings, URS/JAB 8020, URS/John A. Blume \& Associates, Engineers, San Francisco, CA.

Somerville, P., Smith, N., Punyamurthula, S., and Sun, S., 1997. Development of Ground Motion Time Histories for Phase 2 of the FEMA/SAC Steel Project, SAC/BD-97/04, SAC Joint Venture.

Steinbrugge, K. V., and Algermissen, S. T., 1990. Earthquake Losses to Single-Family Dwellings: California Experience, Bulletin 1939, U.S. Geological Survey, Washington, D.C. 
Stewart, W. G., 1987. The Seismic Design of Plywood Sheathed Shear Walls, Ph.D. thesis, Department of Civil Engineering, University of Canterbury, 395 pp.

Sucuoglu, H., and Vallabhan, C. V. G., 1997. Behavior of window glass panels during earthquakes, Earthquake Spectra 19 (8), 685-694.

U.S. Coast and Geodetic Survey, 1969. Studies in Seismicity and Earthquake Damage Statistics, Washington, D.C.

VSP Associates, 1992. FEMA 277-A Benefit-Cost Model for the Seismic Rehabilitation of Buildings, Federal Emergency Management Agency, Washington, D.C.

Wald, D. J., Quitoriano, V., Heaton, T. H., and Kanamori, H., 1999. Relationships between peak ground acceleration, peak ground velocity and modified Mercalli intensity in California, Earthquake Spectra 15 (3), 557-564.

Wills, C. J., Petersen, M., Bryant, W. A., Reichle, M., Saucedo, G. J., Tan, S., Taylor, G., and Treiman, J., 2000. A Site Conditions Map for California Based on Geology and Shear Wave Velocity, California Geological Survey, Sacramento, CA, 41 pp.

(Received 13 May 2004; accepted 5 May 2005) 